\title{
With humour and hope
}

\author{
FOB DOC: A Doctor on the Front Lines in \\ Afghanistan: A War Diary \\ Captain Ray Wiss MD \\ Douglas \& McIntyre; 2009. \\ 194 pp $\$ 32.95$
}

$\mathrm{W}$

hen Dr. Ray Wiss volunteered to serve with the Canadian Forces in Afghanistan, a mission in which he deeply and passionately believed, he left behind a successful medical and business practice, a devoted wife and young daughter and friends from all over the world.

He began keeping an electronic diary that he emailed home regularly, both to explain his choice to his friends and to leave a record for his two-yearold daughter. As the readership of his diary grew, Wiss was increasingly pressured to share his experiences with a larger audience. That encouragement led to the publication of FOB DOC.

The big, bold capital letters of $F O B$ $D O C$ (short for forward operating base doctor) over the picture of Wiss in full gear may give the impression that this is a book exclusively about battles and engagements, troop figures and movements. Rest assured it is anything but that. It is a narrative told as a sequence of days and anecdotes that, when stitched together, weave the terror, humour, bravery, humanity and, ultimately, nobility of the Canadian and Afghan soldiers, medical technicians and people into an engaging and eminently readable story.

Making a conscious effort to paint a complete picture of Afghan and deployed Canadian culture, Wiss trains a consistently witty and sometimes wry eye on life abroad. He describes the dreaded 'talibug' ("a thing that looks like a wasp but is the size of a hummingbird"); when to exercise necessary bodily functions ("time your bowel movements for midday, when the cold plastic latrine seats are barely tolerable"); the location of the not-quite-so-famous "Field of Outhouses" (complete with picture), and the

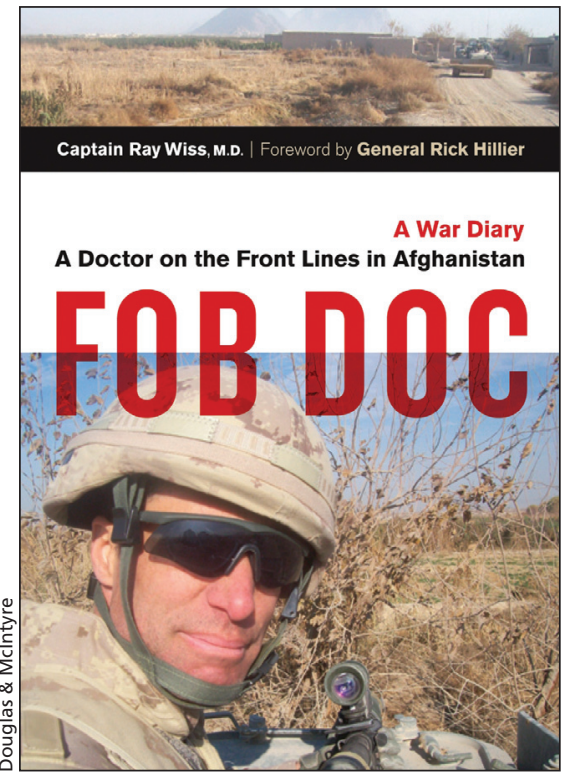

dirty little secret of how the Tim Horton's in Kandahar, repudiated to be the most successful franchise in the world, sells more French vanilla coffee than any other outlet.

Humour aside, Wiss also confronts the serious, the tragic and the intensely personal. He describes the common fears that soldiers experience, "dying, killing, sights and sounds, failure and the unknown ... [and] mutilation and disfigurement," musing on the simple pleasure of having all of one's limbs. He illustrates the raw courage young Canadian men and women display when they take a light armoured vehicle over ground sure to be littered with improvised explosive devises. Finally, he portrays the resilience of an Afghan people who have withstood the Taliban-sponsored genocide of Mazar-i-Sharif and the Taliban enacted acid attacks on school-attending girls. Wiss's grappling with these issues, and his personal resolve to spare his young daughter such a world, comes through in illuminating and conversational prose.

In the medical anecdotes, the serious and the silly mix in a way that takes the reader from hilarity to grief to understanding. Within a week of arriving at his

\section{initial FOB, Wiss finds himself con- fronted with his first multiple casualty event as his team rapidly executes hem- orrhage control, trauma surveys, spinal stabilization and rapid evacuation to a higher level of care. Less than two weeks later, he encounters what happens when a slightly deranged Afghan National Army soldier gets "the erection that would not die" from off-market yohim- bine (a chemical found in Pausinystalia yohimbe tree bark). \\ Like many before him, war is long periods of boredom punctuated by stark terror; fortunately for Wiss and the reader, however, some of the terror is leavened with the kind of humour one cannot make up. \\ $F O B D O C$ is many things. It is a short lesson in Afghan history, a retrospective on Canadian involvement in world con- flict and an exhortation to become knowl- edgeable and involved in the political process. It is a look at medical practice in an austere environment, a memorial to those brave Canadians who died in their nation's service and an insight into how one man coped with his decision to serve in a war-torn and desolate country. In addition, $F O B D O C$ is one thing more: it is a chance to do good. Wiss has arranged for all of his royalties to be donated to the Military Families Fund. That Ray Wiss is a man who believes in the power of one shines through his words and deeds - both of which are opened to you through this remarkable little work.}

Aaron Saguil MD MPh

Assistant Program Director

Dwight D. Eisenhower Army Medical Center

Family Medicine Residency

Fort Gordon, USA

During 2007 and 2008 the author was chief and assistant chief of Primary Care with the North Atlantic Treaty Organization (NATO) Role 3 Multinational Medical Unit at Kandahar Air Field, where he worked with Dr. Wiss. 